\title{
DESIGNING TOWARDS A FIRE-RESISTANT NEIGHBORHOOD IN SURABAYA, INDONESIA
}

\author{
Prananda Navitas \\ Faculty, Department of Urban and Regional Planning, Sepuluh Nopember Institute of Technology, Surabaya, Indonesia, \\ prananda.navitas@gmail.com
}

\begin{abstract}
The way the built environment is shaped greatly affects its performance in providing a container of activities for its users. Being the second largest city in Indonesia after Jakarta, Surabaya has very high population and building density. Though the city is not prone to any natural disasters, the current population and building density make it prone to man-made disasters such as flooding and urban fires. This study was built on the idea that good environmental design can lower urban fire vulnerability.

Built environment components were identified using Lynch's urban design criteria while Cai and Wang provided basic guidance to the redesign of the built environment with their Safety-based Urban Design idea.

The outcome of this endeavor was an environmental design approach that applied psychological safety, behavioral safety, defense for safety and safety against disaster values into the built environment's paths, edges, nodes, districts and landmarks. This paper concludes that good environmental design can improve resilience by intervening in all stages of a disaster or an emergency situation. It can support mitigation efforts thus increasing disaster preparedness. Environmental design can also make a difference in responding to an emergency situation. The most likely approach to improving resilience in urban areas is to acknowledge both anthropogenic and bio-physic aspects that make up the environment. Urban fire awareness must be raised as the physical environment is shaped one component at a time.
\end{abstract}

Keywords: urban fire, vulnerability, environmental design, safety-based urban design

\section{INTRODUCTION}

Uncontrolled fire remains one of the major causes of death and property damage in today's society $[1,2]$. A fire outbreak in a densely built and densely populated urban area will easily propagate to adjacent buildings one after another. As is noted by Rosen, some of the well-known urban fires are the Chicago, Boston, and Baltimore fires that occurred in 1871, 1872, and 1904 respectively [3]. These occurrences are responsible for extensive damage on the urban environment and the cause of numerous fatalities [4]. Proper preparedness in the event of a fire therefore is essential to safeguard life and minimize property damage.

Surabaya is not prone to any natural disasters. However, the structural processes that accelerate urbanization instead, expose the city to man-made disasters such as floods and fires. The Surabaya Fire Department (SFD) has recorded 4,460 cases between 1996 and 2011, causing 70 casualties, injuring 179 people, and a total of IDR 430,849,500,000.- (approx. USD $37,866,559.44$ ) in property damage. Most of the fires that had occurred in Surabaya were caused by electrical malfunction. In an attempt to manage the urban fire phenomena, the SFD classified the 31 districts in Surabaya into five risk categories: very high risk, high risk, medium, low risk, and very low risk. In creating these categories, the SFD took the following factors into consideration: population density, building density, fire occurrence data, building/structural conditions, land use intensity, and water availability. The following map displays the geographical position of the 31 districts and the five risk categories:

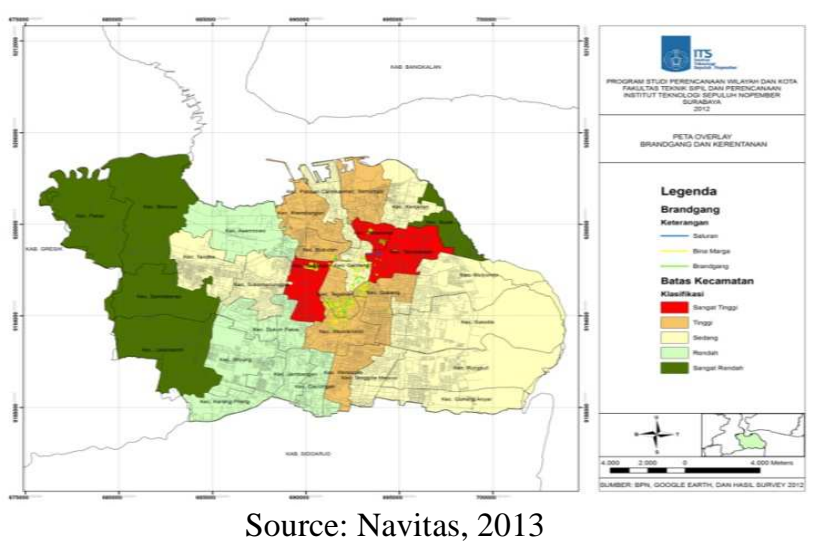

Fig- 1 Surabaya Fire Risk Map 
As

Fig- 1 shows, most parts of Surabaya fall into the very low risk to medium risk categories. The western part of Surabaya is mostly very low risk since population and building density there are still low. Medium risk areas are concentrated around the eastern part of Surabaya. There are only three districts that fall into the very high risk category: Sawahan, Simokerto, and Tambaksari.

The SFD ranked Sawahan as the district with the highest population density (78.9), building density (89.63), and building condition (55.52) indexes compared to other districts in the greater sub-division (South Surabaya) but scored only 64.29 (fire occurrence index), and has an average water availability index (52.94). Simokerto, on the other hand, has the highest population and building densities in the whole city (scoring 100.00 on both indexes) but comes second on the building condition (39.54), and water availability (27.78) indexes, and third in fire occurrences (40.48). Of the three districts, Tambaksari has the lowest population density (60.72), the highest building condition score (100), and the highest fire occurrence (71.43). It also has the second highest land proportion index (97.71) compared to the other two districts in the very high risk category.

Table- 12011 Fire Occurrence per District

\begin{tabular}{|c|c|c|c|}
\hline District & Sub-district & Occurrence & $\begin{array}{l}\text { Type/Cause } \\
\text { of fire }\end{array}$ \\
\hline \multirow{8}{*}{ Sawahan } & Banyu Urip & 1 & $\begin{array}{l}\text { Residential } \\
\text { fire }\end{array}$ \\
\hline & $\begin{array}{l}\text { Dukuh } \\
\text { Kupang }\end{array}$ & 1 & Gas stove \\
\hline & $\begin{array}{l}\text { Kupang } \\
\text { Krajan }\end{array}$ & 2 & $\begin{array}{l}\text { Residential } \\
\text { fire }\end{array}$ \\
\hline & \multirow{3}{*}{ Pakis } & \multirow{3}{*}{5} & Open fire \\
\hline & & & $\begin{array}{l}\text { Public } \\
\text { building }\end{array}$ \\
\hline & & & $\begin{array}{l}\text { Vehicular } \\
\text { fire }\end{array}$ \\
\hline & Petemon & 3 & $\begin{array}{l}\text { Residential } \\
\text { fire }\end{array}$ \\
\hline & Putat Gede & 1 & Open fire \\
\hline \multirow{5}{*}{ Simokerto } & \multirow{2}{*}{ Simokerto } & \multirow{2}{*}{2} & $\begin{array}{l}\text { Public } \\
\text { building }\end{array}$ \\
\hline & & & $\begin{array}{l}\text { Residential } \\
\text { fire }\end{array}$ \\
\hline & $\begin{array}{l}\text { Simolawan } \\
\mathrm{g}\end{array}$ & 2 & $\begin{array}{l}\text { Residential } \\
\text { fire }\end{array}$ \\
\hline & \multirow{2}{*}{ Tambakrejo } & \multirow{2}{*}{4} & $\begin{array}{l}\text { Public } \\
\text { building }\end{array}$ \\
\hline & & & $\begin{array}{l}\text { Residential } \\
\text { fire }\end{array}$ \\
\hline Tambaksari & Gading & 2 & Open fire \\
\hline
\end{tabular}

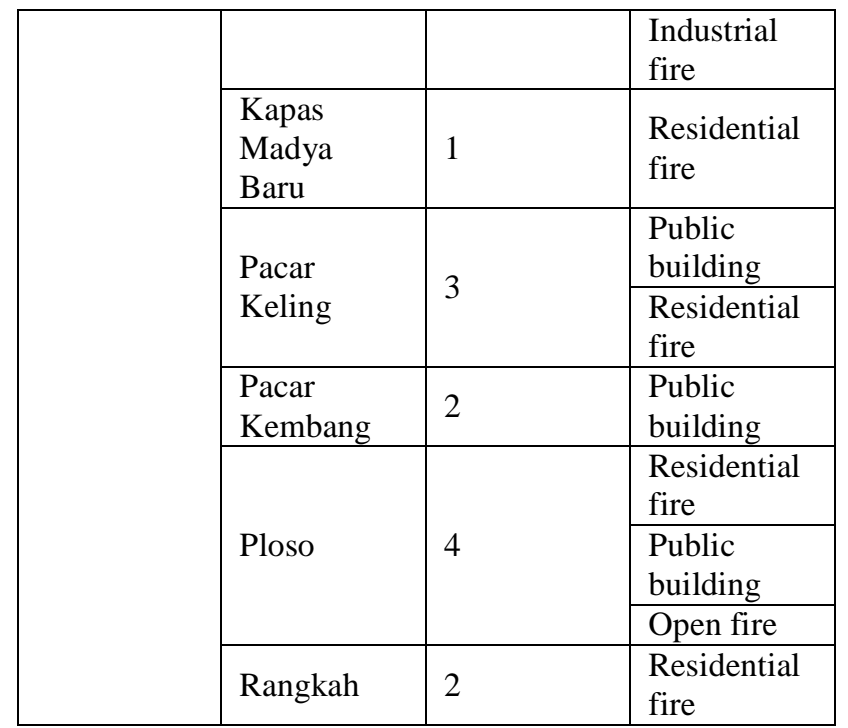

Source: adapted from SFD records, 2012

The table above indicates that the sub-districts of Pakis, Tambakrejo, and Ploso experienced the highest frequency of occurrence compared to other districts that occupy the very high risk category.

\subsection{Disaster Management and Environmental Design}

Disaster Management or Emergency Management is understood as a set of inter-connected activities to reduce risk and describing post-disaster strategies towards recovery [5-8]. The approach includes strategies and activities during the following stages of a disaster or an emergency situation:

1. Pre-disaster (mitigation and disaster preparedness): though disaster mitigation and disaster preparedness may seem very similar. Mitigation relates to activities or measures in avoiding a disaster, or minimizing the damage it causes. Preparedness on the other hand, contains all activities and measures in case a disaster strikes;

2. During a disaster (response): the activities carried out during response are related to measures taken during the course of a disaster, or directly after it strikes, aimed at reducing casualties and prevent further damages;

3. Post disaster (recovery): once a disaster has seized to occur, efforts to repair the damages and restore the environment to its pre-disaster state can take place. This stage is also known as the bounce back stage.

The activities contained in the three stages mentioned above are inter-connected to form a cycle because experiences from each stage become input to prepare for future disasters. Documented response experiences will provide valuable input for better mitigation and preparedness which in turn will result in better response. 


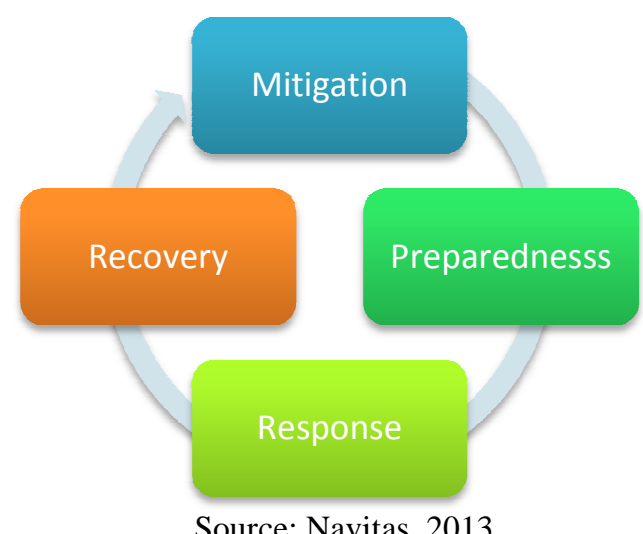

Source: Navitas, 2013

Fig- 2 Disaster Management Cycle

The basic content of urban design is creating places [9]. With numerous contributing factors, Thwaites [10] believes a successful urban place is much more of a miracle than a goal. Despite that, Cai and Wang [11] mention environmental quality is the basic goal of, and the major deciding factor of the success of urban design. In their perspective, public safety is a determining factor in defining environmental quality. An aesthetically pleasing urban environment may not be considered a successfully designed space if it cannot guarantee its users' safety.

There lie three opportunities in which environmental design can normatively and creatively intervene in the disaster management cycle:

1. Mitigation: as fire propagates through convection, conduction, and thermal radiation $[4,12,13]$ the design of the environment should allow some distance between structures, or have a fire-resistant structure (such as a wall) erected between them;

2. Preparedness: having clearly designated escape routes and informative signage will be very helpful for residents of dense urban locales. Fire hydrant posts should also be available throughout fire-prone areas to ensure water availability and fire engine reach.;

3. Response: improve paths on which people and vehicles circulate. Paths or lanes should be physically able to accommodate the width, length, and maneuverability of fire fighting vehicles.

\subsection{Problem Statement}

The urban fabric in Indonesia generally consists of modern structures and vast kampung settlements. These settlements generally manifest and develop themselves incrementally. Having narrow lanes and being densely built, kampung neighborhoods are difficult to access, and when a fire outbreak occurs it propagates to adjacent buildings easily, causing extensive damage in a short amount of time [14]. Spatial plans and strategic management documents exist as non-structural instruments of mitigation thus already covering urban safety aspects [11]. However, they are often too program-oriented, and acknowledge the distribution of spatial phenomena in a two-dimensional manner only. The built environment in reality is a three-dimensional landscape.

\subsection{Scope of Study}

This paper will discuss the search for an environmental design approach in the sub-district of Pakis, located in the district of Sawahan. Pakis has the most fire outbreaks according to the latest SFD records (see Table- 1). A corridor was chosen to represent the sub-district since it has a variety of land usage though dominated by residential activities.

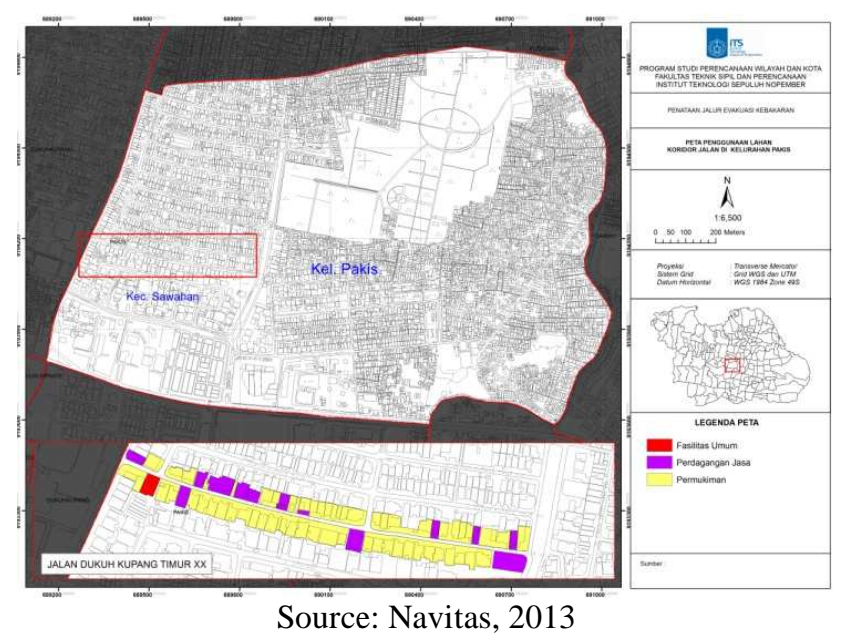

Fig- 3 Pakis Sub-district

\section{COMPONENTS OF THE BUILT ENVIRONMENT}

Lynch [15] described the built environment as a composition of five basic components: paths, edges, nodes, districts, and landmarks. The following passages will discuss each component in detail.

\subsection{Paths}

Paths are linear elements that function as a means of movement and circulation. They can be represented by a network of roads, canals, or even railways. To most people, this is the most dominant element in building the environmental image. Other components are usually arranged along the network of paths.

\subsection{Edges}


Edges are defined as linear elements that do not function as circulatory means. Edges are the border between two or more areas, a linear cut-off (e.g. a coastline or an imaginary plane formed by two or more physical structures), or represented by a physical structure.

\subsection{Nodes}

Nodes are represented by strategic points in the locale. They can be starting points, or points of destination. Nodes can be intersections where two or more modes of transportation meet (an interchange), or where multiple activities intersect.

\subsection{Districts}

Districts are segments of a locale with homogeneity; having a common, defining characteristic. Districts can be easily identified from zoning maps.

\subsection{Landmarks}

Landmarks are the physical manifestation of a node. They can be represented by a physical structure (building or infrastructure), signage, or geographical features. Landmarks can be located within a locale, or be at a certain distance.

\section{SAFETY-BASED URBAN DESIGN}

According to Cai and Wang [11], to ensure safety environmental design must consider the psychological and behavioral aspects as well as environmental aspects. The following sections will discuss the four aspects of Safetybased Urban Design: psychological safety, behavioral safety, defense for safety, and safety against disaster.

\subsection{Psychological Safety}

An environment's level of psychological safety is influenced by many factors. Spatially, the degree of psychological safety is related to people's level of privacy and how much they have control over it. Lynch [15] pointed out that the degree of control people have over the environment is related to their spatial orientation. In other words, it is related to legibility (clarity), where parts of the urban environment can be recognized and organized into a coherent pattern.

\subsection{Behavioral Safety}

Elements and configuration of the urban environment may pose physical harm towards human activities. Behavioral safety is deeply rooted in environmental behavior science and ergonomics. Creating a more accommodating environment can be achieved by improving form, structure, and function type of the road-surrounding environment landscape.

\subsection{Defense for Safety}

The way an urban environment is spatially configured should reduce, or totally discourage inappropriate and disruptive behavior. Clear division of public and private as well as community surveillance can help protect citizen's safety [16].

\subsection{Safety against Disaster}

Site selection and spatial form of the environment have direct influence on the resistance capability of the environment towards disasters. Before deciding on a location for vital infrastructure, a careful assessment of its future location is important.

\section{DESIGN PROJECT}

\subsection{Design Approach}

The design approach is a formulated from the identification of the components of the built environment overlaid with the principles of Safety-based Urban Design. The table below displays the overlay of the two approaches:

Table- 2 Design Approach Matrix

\begin{tabular}{|l|l|l|l|l|}
\hline & $\begin{array}{l}\text { Psycho- } \\
\text { logical } \\
\text { Safety }\end{array}$ & $\begin{array}{l}\text { Behavio- } \\
\text { ral Safety }\end{array}$ & $\begin{array}{l}\text { Defense } \\
\text { for Safety }\end{array}$ & $\begin{array}{l}\text { Safety } \\
\text { Against } \\
\text { Disaster }\end{array}$ \\
\hline Path & $\begin{array}{l}\text { Improve } \\
\text { legibility } \\
\text { of path }\end{array}$ & $\begin{array}{l}\text { Improve } \\
\text { legibility } \\
\text { of path }\end{array}$ & $\begin{array}{l}\text { Ensure } \\
\text { path is } \\
\text { free from } \\
\text { obstruct- } \\
\text { tion }\end{array}$ \\
\hline Edge & - & - & - & - \\
\hline Node & $\begin{array}{l}\text { Ensure } \\
\text { path } \\
\text { legibility }\end{array}$ & - & - & $\begin{array}{l}\text { Strategic } \\
\text { signage } \\
\text { placemen } \\
\text { t points }\end{array}$ \\
\hline District & - & - & $\begin{array}{l}\text { Increase } \\
\text { homogen } \\
\text { eity }\end{array}$ \\
\hline $\begin{array}{l}\text { Land- } \\
\text { mark }\end{array}$ & $\begin{array}{l}\text { Ensure } \\
\text { path } \\
\text { legibility }\end{array}$ & $\begin{array}{l}\text { Ensure } \\
\text { path } \\
\text { legibility }\end{array}$ & $\begin{array}{l}\text { Strategic } \\
\text { signage } \\
\text { placemen } \\
\text { t }\end{array}$ & $\begin{array}{l}\text { Strategic } \\
\text { signage } \\
\text { placemen } \\
\text { tacen }\end{array}$ \\
\hline
\end{tabular}

Source: Navitas, 2013

Table- 2 indicates the environmental design should ensure legibility of paths to increase psychological and behavioral safety. This can be achieved by adding landmarks in the form of signage that are strategically placed to emphasize nodes. Signage placement should not only ensure visual clarity but also ensure signage safety against acts of vandalism. Paths should also be kept free from obstruction to ensure maximum accessibility. 


\subsection{Further Study}

This study has yet to consider local building regulations and fire safety standards. Once acknowledged, the regulations and standards will serve as a tool to identify deviations in the study area. Further steps to take are:

1. Field survey: conduct a walkthrough through the study location and document deviations from local regulations and standards;

2. Assessment: assess the degree of deviation; and

3. Formulate recommendations and strategies for environmental improvement.

\section{CONCLUSIONS}

Good environmental design can improve resilience by intervening in all stages of a disaster or an emergency situation. It can support mitigation efforts thus increasing disaster preparedness. Environmental design can also make a difference in responding to an emergency situation. However, a total overhaul of the built environment, though possible, is not feasible due to numerous reasons. The most likely approach to improving resilience in urban areas is to acknowledge both anthropogenic and bio-physic aspects that make up the environment. Urban fire awareness must be raised as the physical environment is shaped one component at a time.

\section{ACKNOWLEDGEMENTS}

The author would like to express his gratitude to the Institute for Research and Public Outreach (LPPM ITS) for funding this research (contract no. 013674.212/IT2.7/PN.08.01/2013) and other parties who have supported this research.

\section{REFERENCES}

[1] Poerbo, H., Utilitas Bangunan. 3 ed. 1998, Jakarta: Djambatan.

[2] Schneid, T.D. and L. Collins, Disaster management and preparedness. Occupational safety and health guide series. 2001, Boca Raton, Fla: Lewis Publishers. 247 S.

[3] Rosen, C.M., The limits of power: great fires and the process of city growth in America. 1986, Cambridge [Cambridgeshire] ; New York: Cambridge University Press. xii, 395 p.

[4] Himoto, K. and T. Tanaka, Development and validation of a physics-based urban fire spread model. Fire Safety Journal, 2008. 43(7): p. 477-494.

[5] Dahl, E.L. The Disaster Management Cycle. 2011.

[6] Khan, H., L.G. Vasilescu, and A. Khan, Disaster management cycle - a theoretical approach. Management \& Marketing, 2008. VI(1): p. 43-50.

[7] Ali, S.H. and A. Novogradec, Disasters and Emergency Preparedness, in Encyclopedia of Global Health, Y.
Zhang, Editor. 2008, Sage Publications: Thousand Oaks. p. 532-535.

[8] Navitas, P., Creativity in the Face of Danger: Urban Design as Creative Intervention Measure against Urban Disaster, in 23rd Pacific Conference of the RSAI 20132013: Bandung, Indonesia.

[9] Carmona, M. and S. Tiesdell, Urban design reader. 1. ed. 2007, Amsterdam: Elsevier/Architectural Press. vii, $375 \mathrm{~S}$.

[10] Thwaites, K., et al., Urban sustainability through environmental design : approaches to time - people and place responsive urban spaces, 2007, Taylor \& Francis: London.

[11] Cai, K. and J. Wang, Urban design based on public safety--Discussion on safety-based urban design. Frontiers of Architecture and Civil Engineering in China, 2009. 3(2): p. 219-227.

[12] Schroll, C., The Essentials of Fire Safety. Professional Safety, 2006. 51(10): p. 42-44.

[13] Ramli, S., Petunjuk Praktis Manajemen Kebakaran. 2010, Jakarta: Dian Rakyat.

[14] Sufianto, H. and A.R. Green, Urban fire situation in Indonesia. Fire Technology, 2012. 48(2): p. 367-387.

[15] Lynch, K., The image of the city. 34. pr. ed. Publication of the Joint Center for Urban Studies. 1960, Cambridge, Mass.[u.a.]: MIT PRESS. VII, 194 S.

[16] Jacobs, J., The death and life of great American cities. Vintage Books ed. 1992, New York: Vintage Books. $458 \mathrm{p}$.

\section{BIOGRAPHIE:}

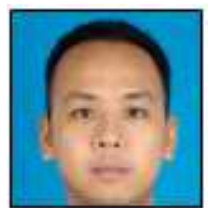

Prananda joined the DURP in 2009. Before that he was a professional architect and interior designer. His current research interest revolves around urban design and place-making. 